\title{
Longitudinal Half-and-Half Nails: Case Report and Review
}

\author{
Philip R. Cohen \\ Department of Dermatology, University of California San Diego, La Jolla, CA, USA
}

\section{Established Facts}

- Transverse half-and-half nails (Lindsay's nails) can be observed in patients with chronic renal disease.

- Longitudinal half-and-half nails are rare and have only been noted in a patient with hallux valgus deformity.

\section{Novel Insights}

- Longitudinal half-and-half nails can occur on the thumbs or great toes and may be idiopathic or associated with chronic trauma to the digits.

\section{Keywords}

Half-and-half nails · Horizontal · Leukonychia · Lindsay's nails · Linear · Longitudinal · Nails · Transverse · White

\begin{abstract}
Half-and-half nails were originally described as a transverse leukonychia in patients with chronic renal disease; other conditions (such as Behcet's and Crohn's disease) and medications (such as isoniazid) have also been associated with the nail changes. However, longitudinal half-and-half nails (affecting the medial aspects of the nails) have previously been reported on the great toes of an older woman and, in the present case, on the thumbs of an elderly man; neither person had Behcet's, Crohn's, or kidney disease or was receiving isoniazid. The woman had a true leukonychia, bilateral hallux valgus deformity, and chronic trauma to her me-
\end{abstract}

\section{KARGER}

(c) 2018 S. Karger AG, Basel

E-Mail karger@karger.com

www.karger.com/sad dial nail folds. The man had a nontraumatic apparent leukonychia and bilateral koilonychia; the non-white lateral area of his left thumb also had a linear groove (resulting from a digital mucous cyst on the proximal nail fold) and subungual hyperkeratosis. In conclusion, longitudinal half-andhalf nails are a rare phenomenon that has not been associated with either a systemic disease or medication; the acquired nail change can present either as an idiopathic finding or occur secondary to chronic trauma. @ 2018 S. Karger AG, Basel

\section{Introduction}

Half-and-half nails, frequently associated with chronic renal disease, typically present as a transverse leukonychia $[1,2]$. Longitudinal half-and-half nails, albeit 


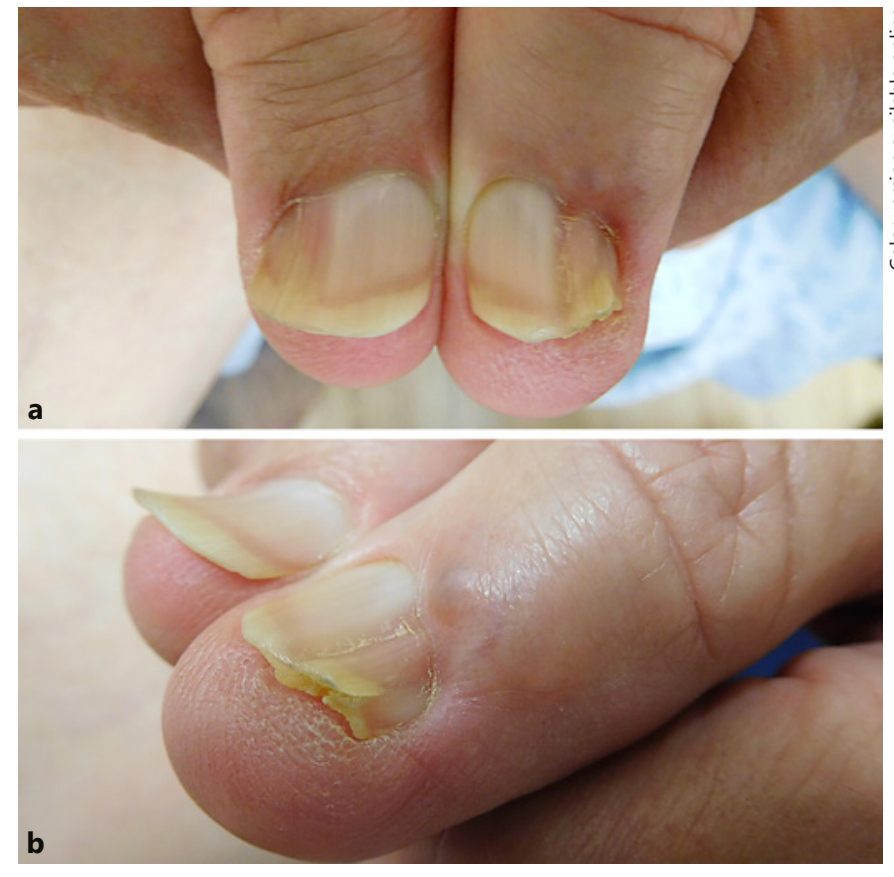

Fig. 1. Frontal (a) and side (b) views of bilateral longitudinal halfand-half nails on the thumbs of a 74-year-old man. Linear broad bands of leukonychia are present on the medial half of each thumbnail. Koilonychia is noted on both thumbnails. A mucous cyst is observed on the proximal nail fold of the left thumb with a longitudinal nail plate grove that extends to the distal free edge of the nail.

only once, have been reported on the great toenails of a woman with bilateral hallux valgus deformity [3]. A man with bilateral longitudinal half-and-half nails of his thumbs is described and the features of the individuals with this unique variant of leukonychia are summarized.

\section{Case Report}

A 74-year-old man without Behcet's, Crohn's, or kidney disease presented for a skin evaluation of an asymptomatic rash on his abdomen. His past medical history was significant for mild aortic valve regurgitation and mitral valve prolapse with severe mitral valve regurgitation, hyperlipidemia, hypothyroidism, and Parkinsonism. His current daily medications included aspirin, atorvastatin, atropine ophthalmic solution, benzonatate, carbidopa-levodopa, entacapone, and levothyroxine. He was not a gardener and had no exposure to organic solvents.

Cutaneous examination showed a $10 \times 10 \mathrm{~cm}$ red-brown plaque on his mid abdomen; a potassium hydroxide preparation of skin scrapings was positive for fungal hyphae. Longitudinal leukonychia of the medial aspects of both of his thumbs, of unknown duration, and bilateral koilonychia were incidental asymptomatic findings (Fig. 1, 2). The broad white band extended from the proximal nail fold and approached the distal free nail edge; potassium hy-

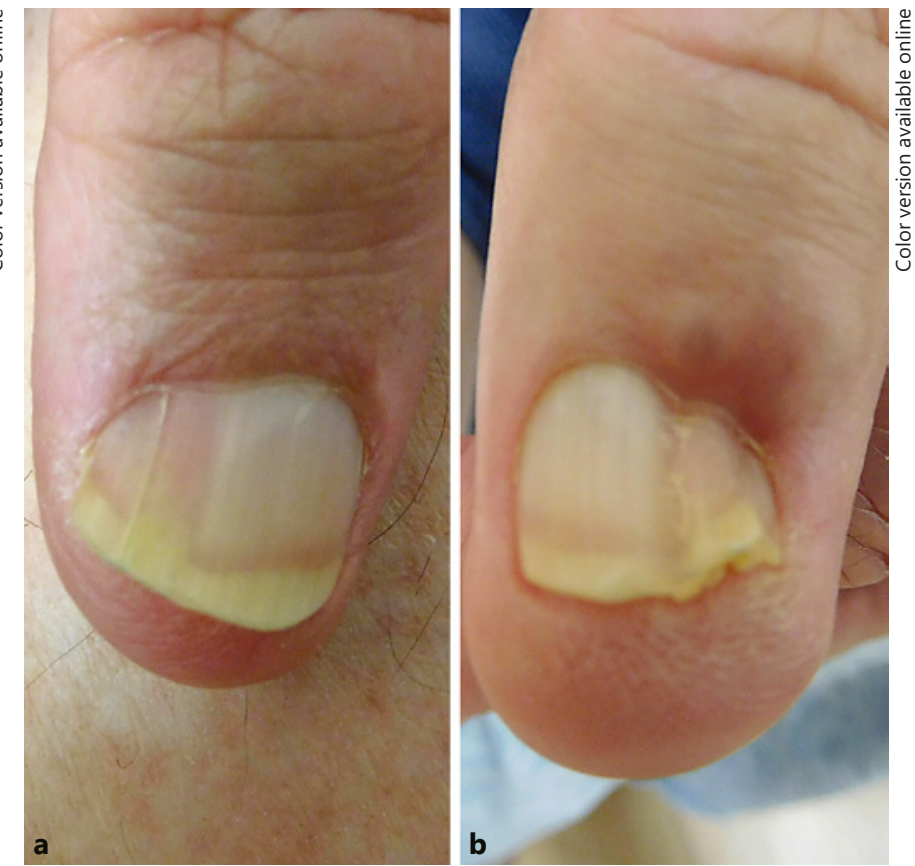

Fig. 2. Closer views of longitudinal half-and-half nails on the right (a) and left (b) thumbnails showing medial linear broad bands of leukonychia. The left thumb (b) has a proximal nail fold mucous cyst with an associated linear groove of the nail plate.

droxide preparations of thumbnail scrapings from the white areas and free edge did not show fungal organisms. Not only the medial nail plates of both thumbs, but also the medial and lateral nail folds of both thumbs, and the proximal right thumb nail fold, were normal; a digital mucous cyst was present in the middle of the left thumb proximal nail fold. A longitudinal nail plate groove was present distal to the cyst and there was subungual hyperkeratosis lateral to the groove on the left thumbnail.

His complete blood cell counts (including hemoglobin and hematocrit), serum chemistries (including albumin, blood urea nitrogen, and creatinine), thyroid-stimulating hormone, and lipids (including cholesterol and triglycerides) were all normal. Ciclopirox $0.77 \%$ cream, twice daily, was prescribed for the tinea corporis on his abdomen. No intervention was initiated for the nail changes on his thumbs.

\section{Discussion}

Dr. William B. Bean and Dr. James Clifton observed the clinical features of half-and-half nails in 2 patients with renal disease in 1962 [4]. A year later, Dr. Bean described these nail changes [4]. Subsequently, during 1963 and 1964, Dr. Philip G. Lindsay also observed 4 patients 
Table 1. Features of the patients with longitudinal half-and-half nails

\begin{tabular}{|c|c|c|}
\hline & Case $1[3]$ & Case 2 (current report) \\
\hline Age $^{\mathrm{a}}$, years & 45 & 74 \\
\hline Race & Caucasian & Caucasian \\
\hline Gender & Female & Male \\
\hline Onset of leukonychia & Acquired & Acquired \\
\hline Duration & Unknown & Unknown \\
\hline Systemic disease or drug ${ }^{b}$ & No & No \\
\hline Digit & Bilateral great toes & Bilateral thumbs \\
\hline Leukonychia nail site & Medial & Medial \\
\hline Leukonychia type & True & Apparent \\
\hline Digit condition & Hallux valgus deformity & Digital mucous cyst \\
\hline Nail unit dystrophy & $\begin{array}{l}\text { Medial nail fold: thick, } \\
\text { hyperkeratotic }\end{array}$ & $\begin{array}{l}\text { Koilonychia, linear nail groove, } \\
\text { subungual hyperkeratosis }\end{array}$ \\
\hline Trauma $^{c}$ & Yes & No \\
\hline
\end{tabular}

${ }^{a}$ Age at diagnosis of longitudinal half-and-half nails. ${ }^{b}$ Presence of a systemic disease or drug related to the etiology of the leukonychia nail changes. ${ }^{c}$ Presence or absence of trauma being associated with the leukonychia nail changes.

with this "unique azotemic onychopathy" and coined the term "half-and-half nail" to describe the "distinctive pattern of nail color characterized by some patients with azotemia" [5].

Half-and-half nails are characterized by a white proximal nail plate and a distal nail plate - more than $20 \%$ of the nail - that is either red, pink, or brown $[1,2]$. In contrast, in patients with Terry's nails (which are associated not only with cirrhosis and congestive heart failure, but also chronic renal failure) the distal non-white nail plate is less than $20 \%$ of the nail [6]. Lindsay's half-and-half nails and Terry's nails are both apparent leukonychias since they represent an alteration of the nail bed with normal nail matrix and nail plate; in contrast, the white color in patients with true leukonychias results from modification to the nail matrix and nail plate $[3,6]$.

The discovery of half-and-half nails should prompt the clinician to evaluate the patient for kidney disease. However, half-and-half nails have occurred as an idiopathic finding and have also been associated with other conditions or medications [7-9]. It has been suggested that half-and-half nails may be a cutaneous stigmata for Crohn's disease (with or without accompanying zinc deficiency) and Behcet's disease $[10,11]$. In addition, halfand-half nails have developed in patients receiving isoniazid for the treatment of tuberculosis - with or without drug-induced pellagra [12].

Half-and-half nails were originally considered to only be a transverse leukonychia. However, in May 2016, Wol- lina and Bula [3] described a 45-year-old woman with longitudinal half-and-half nails of her great toes in Skin Appendage Disorders. To the best of my knowledge, the man in this report is the second individual in whom longitudinal half-and-half nails have been observed.

The clinical features of Wollina and Bula's [3] patient and the currently described individual are summarized in Table 1 . The nail changes were acquired; however, their duration prior to the diagnosis is unknown. Neither person had Behcet's, Crohn's, or kidney disease; also, they had not received isoniazid.

The woman was 45 years old and both of her great toenails were affected. The man was 74 years old; his thumbs were both involved. The medial half of the nail was white in each of the patients.

The leukonychia was longitudinal and extended from the proximal nail fold; the white color either reached or approached the free edge of the toenails or fingernails, respectively. The woman had a true leukonychia; the investigators attributed the whitish appearance of her nails to changes in their optical quality and implied that these changes may have been related to her thickened and hyperkeratotic medial nail folds. In contrast, since the affected areas of the man's nail folds and nail matrix were not altered, he had an apparent leukonychia; the medial nail plates of his thumbs - except for their color - were normal.

Dystrophy to the digit or nail was present in both patients. The woman had alteration of her medial nail folds secondary to friction of the toe with her footwear. The 
man had koilonychia of undetermined etiology of both thumbs; he had neither iron deficiency anemia or hemochromatosis nor exposure to toxins that have been associated with this nail plate dystrophy. In addition, the man had not only subungual hyperkeratosis of the lateral aspect of his left thumb but also a longitudinal groove of his left thumbnail resulting from pressure to the nail matrix from the digital mucous cyst located on the proximal nail fold.

Chronic trauma to the digit may have contributed to the true longitudinal leukonychia and resulting half-andhalf nails of the woman. She had bilateral hallux valgus deformity of both great toes, resulting in greater friction to the medial aspect of her toes and the associated nail apparatus; subsequently, she developed medial nail fold calluses and nail plate thickening in the area of leukonychia. The man had a digital mucous cyst on the proximal nail fold of his left thumb; however, his apparent leukonychia did not involve the nail plate distal or lateral to the cyst.

In summary, longitudinal half-and-half nails have been observed on the medial aspects of the great toes of an older woman and the thumbs of an elderly man. The leukonychia was true and possibly associated with bilateral hallux valgus deformity-related chronic trauma to the medial nail folds of the woman. In contrast, the white nail plates of the man's apparent leukonychia were nontraumatic; however, he not only had a unilateral digital mucous cyst-related linear nail plate groove and subungual hyperkeratosis that did not involve the white area of his nail plate but also bilateral koilonychia. To date, longitudinal half-and-half nails are a rare - idiopathic or trauma-related - acquired nail leukonychia that has not been associated with either systemic disease or medication.

\section{Statement of Ethics}

The patient has given his informed consent to publish the photos and details of the case.

\section{Disclosure Statement}

The author declares no conflict of interest.

\section{References}

-1 Manaktala PS, Anand KS, Janardan V, Verma R: Half and half nails (Lindsay's nails) in chronic renal disease. J Assoc Physicians India 2014;62:44-45.

-2 Iorizzo M, Daniel CR, Tosti A: Half and half nails: a past and present snapshot. Cutis 2011; 88:138-139.

3 Wollina U, Bula P: Longitudinal 'half-andhalf nails' or true leukonychia. Skin Appendage Disord 2016;1:185-186.

4 Bean WB: A discourse on nail growth and unusual fingernails. Trans Am Clin Climatol Assoc 1963;74:152-167.
5 Lindsay PG: The half-and-half nail. Arch Intern Med 1967;119:583-587.

6 Witkowska AB, Jasterzbski TJ, Schwartz RA: Terry's nails: a sign of systemic disease. Indian J Dermatol 2017;62:309-311.

7 Verma P, Mahajan G: Idiopathic 'half and half nails. J Eur Acad Dermatol Venereol 2015 29:1452.

8 Ruiz-Villaverde R, Sanchez-Cano D, Martinez-Lopez A, Tercedor-Sanchez J: Reply to: idiopathic 'half and half nails. J Eur Acad Dermatol Venereol 2016;30:e215-e216.

-9 Tercedor J, Lopez Hernandez B, Manuel Rodenas J: Nail diseases in haemodialysis patients: case-control study. Br J Dermatol 2001; 144:445-446.
10 Pellegrino M, Taddeucci P, Mei S, Peccianti C, Fimiani M: Half-and-half nail in a patient with Crohn's disease. J Eur Acad Dermatol Venereol 2010;24:1366-1367.

11 Gonul M, Hizli P, Gul U: Half-and-half nail in Behcet's disease. Int J Dermatol 2014;51:e26e27.

12 Chadwick A, Thwaites V, Holland M, Shahidi M: Half-and-half nails in a patient on antituberculosis treatment. BMJ Case Rep 2017; bcr2017219841. 